\title{
Potential role of cytotoxic T-lymphocyte antigen 2 alpha in secretory activity of endocrine cells in mouse adenohypophysis
}

\author{
Claudius Luziga* \\ Department of Veterinary Anatomy and Pathology, Sokoine University of Agriculture, Morogoro, Tanzania
}

\begin{abstract}
The peptide hormones of the adenohypophysis are produced by proteolytic processing of their prohormone precursors. Cathepsin $\mathrm{L}$ is known to function as a major proteolytic enzyme involved in the production of the peptide hormones. The structure of the propeptide region of cathepsin L is identical to cytotoxic T-lymphocyte antigen-2 alpha (CTLA-2 $\alpha$ ) which is also shown to exhibit selective inhibitory activities against cathepsin L. However, the specific cell types synthesizing CTLA-2 $\alpha$ in mouse adenohypophysis and its functional implications as relevant in vivo have not been demonstrated. In this study, CTLA-2 $\alpha$ expression in the adenohypophysis was evaluated by immunohistochemistry. In both male and female mice, strong immunoreactivity was specifically detected in folliculostellate (FS) cells surrounding endocrine cells which were delineated by CTLA- $2 \alpha$. These findings suggest that the CTLA-2 $\alpha$ may be involved in the proteolytic processing and secretion of the hormones in the adenohypophysis through regulation of cathepsin L.
\end{abstract}

Keywords: Adenohypophysis, CTLA-2 $\alpha$, Immunohistochemistry, Mouse.

\section{Introduction}

The different cell types in the adenohypophysis behave as dynamic populations. The gland has ability to adapt the absolute and relative number of each of its cell types in response to changing physiological demands. Two main cell types have been identified: the chromophobes which act as reserve cells and chromophils which are subdivided into acidophils and basophils (Melmed, 1995). The acidophils exhibit distinct cell boundaries and are further subdivided into two groups: the somatotropes which produce growth hormone and the mammatropes or lactotropes which produce luteotropic hormone or prolactin. The later initiates and maintains the secretion of milk after pregnancy (Levy, 2002). On the other hand, basophils occur in three subpopulations: the thyroptropes which secrete thyrotropic hormone for stimulating synthesis and release of thyroid hormone; the corticotropes which secrete both adenocorticotropic (ACTH) and lipotropic hormones, and the gonadotropes which produce follicle stimulating hormone and luteinizing hormone (LH) (El Etreby and El Bab, 1977; Japon et al., 1994). In males, the LH is also known as interstitial cell stimulating hormone (ICSH) which stimulate production of testosterone hormone by the testicular interstitial cells. Secretory activity of the adenohypophysis is under the neuroendocrine control from the hypothalamus and is also regulated by peripheral endocrine feedback signals. Multistep proteolytic mechanisms are essential for converting prohormone precursors into active hormones (Hook, et al., 1994; 2004). Prohormone processing to release the active hormone is mediated by cathepsins (Loh and Gainer, 1982; Sei et al.,
2003; Funkelstein et al., 2008a; 2008b). In particular, cathepsin $\mathrm{L}$ is shown to participate in biosynthesis of ACTH, $\beta$-endorphin, and alpha-melanocyte stimulating hormone $(\alpha-\mathrm{MSH})$ in secretory vesicles (Hwang et al., 2007; Funkelstein et al., 2008a). It is also involved in the conversion of proenkephalin into active enkephalin peptide neurotransmitter in chromaffin and PC12 cells (Yasothornsrikul et al., 2003) and in the conversion of pro-neuropeptide Y (proNPY) into active NPY peptide in the brain where it functions as a peptide neurotransmitter and as a neuroendocrine hormone (Funkelstein et al., 2008b). Under the pathological conditions, cathepsins have been observed in inflammation, tumor progression, and metastasis (Chen and Platt, 2011). The enzymatic activity of cathepsins is regulated by changes in $\mathrm{pH}$ and their interaction with inhibitors (Kos and Lah, 1998; Levicar et al., 2002). One of the potent and specific inhibitor of cathepsin $\mathrm{L}$ is the cytotoxic T-lymphocyte antigen-2 $\alpha$ (CTLA-2 $\alpha$ ) which is also structurally identical to its propeptide region (Kurata et al., 2003). However, the expression of CTLA-2 $\alpha$ in the adenohypophysis has not been demonstrated. The purpose of this study was to examine, by immunohistochemistry, the cellular localization and distribution pattern of CTLA- $2 \alpha$ in adenohypophysis. This information is important in understanding the mechanisms underlying secretion and regulation of peptide hormones in the gland.

\section{Materials and Methods}

\section{Tissue preparation}

In this study, 10 adult mice (five males and five females) were kept in separate compartments in a small animal 
laboratory house in the controlled conditions of light (12-h light-dark cycles) and temperature $\left(20^{\circ} \mathrm{C}-25^{\circ} \mathrm{C}\right)$. The mice were fed standard laboratory chow and water ad libitum. All the procedures were in compliance with the Ethical Committee of Sokoine University of Agriculture, Tanzania. The mice were anesthetized with sodium pentobarbital ( $60 \mathrm{mg} / \mathrm{kg}$ body weight) by intraperitoneal injection. Transcardiac perfusion with $0.01 \mathrm{M}$ phosphate-buffered saline (PBS; pH 7.4) was performed followed by $4 \%$ paraformaldehyde (PFA; Sigma-Aldrich, St. Louis, MO) in 0.1 phosphate buffer (PB; $\mathrm{pH}$ 7.4). After sacrificing the mice, pituitary (hypophyses) glands were dissected, followed by fixation in $4 \%$ PFA for $2 \mathrm{~h}$ at $4{ }^{\circ} \mathrm{C}$. The histopathology procedure was done as described previously with minor modifications (Slaoui and Fiette, 2011). In brief, the tissues were processed in ascending ethanol series to paraffin wax. Then, tissue blocks were made and cut at $4 \mu \mathrm{m}$ thick to produce tissue sections. Some sections were used for Hematoxylin and Eosin staining (H\&E) and others for immunohistochemistry as described previously (Cuello, 1993) using diaminobenzidine tetra-hydrochloride (DAB) for the detection of binding sites and immunofluorescence as described by Sander et al. (1991), with minor modifications.

\section{Routine H\&E staining}

Tissue sections were deparaffinized in xylene followed by rehydration through a descending ethanol series to phosphate-buffered saline (0.01-M PBS; pH 7.4). The sections were stained using $\mathrm{H} \& \mathrm{E}$ in order to examine the histological organization and cellular components of the adenohypophysis.

\section{Antibody generation}

The polyclonal CTLA- $2 \alpha$ antibody against CTLA- $2 \alpha$ protein was obtained through affinity chromatography column with recombinant CTLA- $2 \alpha$ conjugated resin after immunization in rabbit and antiserum preparation as previously described using recombinant protein of the CTLA- $\alpha$ molecule with N-terminal poly-histidine tag (Takahashi et al., 1993). The specificity of the purified antibody was characterized by Western blot as reported previously (Luziga et al., 2008).

\section{Immunohistochemical examination using diaminobenzidine tetra-hydrochloride chromogen}

Deparaffinization of tissue section was done as in $\mathrm{H} \& \mathrm{E}$ staining. Tissue sections were immersed in a solution of $0.3 \%$ hydrogen peroxide $(\mathrm{v} / \mathrm{v})$ in distilled water for 30 $\mathrm{min}$ at the room temperature (RT) to inhibit endogenous peroxidase activity, followed by washing $(3 \times 5 \mathrm{~min})$ in PBS. Sections were then incubated with $10 \%$ goat normal serum for $30 \mathrm{~min}$ at RT to block non-specific binding followed by incubation overnight in a dark, humid chamber at $4{ }^{\circ} \mathrm{C}$ with the CTLA- $2 \alpha$ antibody diluted at ratio of 1:500 in PBS. For negative control, PBS was applied in place of CTLA- $2 \alpha$ antibody. Sections were then washed $(3 \times 5 \mathrm{~min})$ in PBS followed by incubation for $30 \mathrm{~min}$ at RT with biotinylated goat anti-rabbit IgG (MP Biomedicals Inc., Germany).
Sections were then washed $(3 \times 5 \mathrm{~min})$ in PBS before the incubation with streptavidin-peroxidase conjugate for $20 \mathrm{~min}$ at RT. The tissue section were then incubated for $3-5$ min with a medium containing $0.05 \% 3,3^{\prime}-\mathrm{DAB}$, $0.01 \%$ hydrogen peroxide, and $0.05-\mathrm{M}$ Tris- $\mathrm{HCl}, \mathrm{pH} 7.6$ to visualize binding sites followed by counterstaining with hematoxylin for $30 \mathrm{~s}$ in order to stain the nucleus. The tissues were then rinsed for 15 min in running tap water followed by dehydration through a graded ethanol series, clearance and mounting by distyrene, plasticizer and xylene (DPX). Binding sites were assessed using Olympus BH-2 microscope fitted with Olympus camera. Immunofluorescence analysis

To confirm the presence of CTLA- $2 \alpha$ protein in adenohypophysis, immunofluorescence was performed on the tissue sections. The initial steps in processing tissues remained the same as for streptavidin-peroxidase method. However, the sections were incubated overnight at $4^{\circ} \mathrm{C}$ with CTLA-2 $\alpha$ (1:500) IgG in PBS, pH 7.4, then washed $(3 \times 5 \mathrm{~min})$ in PBS followed by incubation with Alexa Fluor ${ }^{\circledR}$ 488-conjugated chicken anti-rabbit IgG (fluorescein isothiocyanate (FITC)) at a dilution of 1:100 (Molecular Probes) for $1 \mathrm{~h}$ at RT. The tissues were then washed $(3 \times 5 \mathrm{~min})$ in PBS and mounted. Immunolabeling was analyzed using Olympus BH-2 microscope fitted with Olympus camera.

\section{Results}

\section{Histological examination findings}

H\&E stained sections showed that the adenohypophysis was of normal morphological organization. The gland was formed of groups of cells arranged in cords or clusters and separated by irregular blood capillaries. The cells were comprised two distinct types: chromophils and chromophobes. The chromophils are usually classified according to their shape, size, nucleus position, and the staining affinity of their granules into two major subtypes: acidophils and basophils. The acidophils generally showed distinct cell boundaries and cytoplasm was filled with specific granules that stained pink with eosin. The basophils displayed light blue nuclei and cytoplasm was filled with specific granules that stained purple with hematoxylin. The chromophobes were represented by folliculostellate (FS) cells that appeared pale in color and showed long cytoplasmic processes that surrounded adjacent endocrine cells and were in close contact with blood capillaries (Fig. 1).

\section{CTLA-2a localization in FS cells}

High levels of immunoreactivity for CTLA- $2 \alpha$ in both male and female mice were observed in FS cells. These cells were recognized by their special tendency to extend long cytoplasmic processes to surround adjacent endocrine cells and being in close contact with capillaries. The endocrine cells were not associated with CTLA-2 $\alpha$ expression. The endocrine cell surrounded by FS cells are thought to be somatotropes and corticotropes, which are usually located in the lateral 


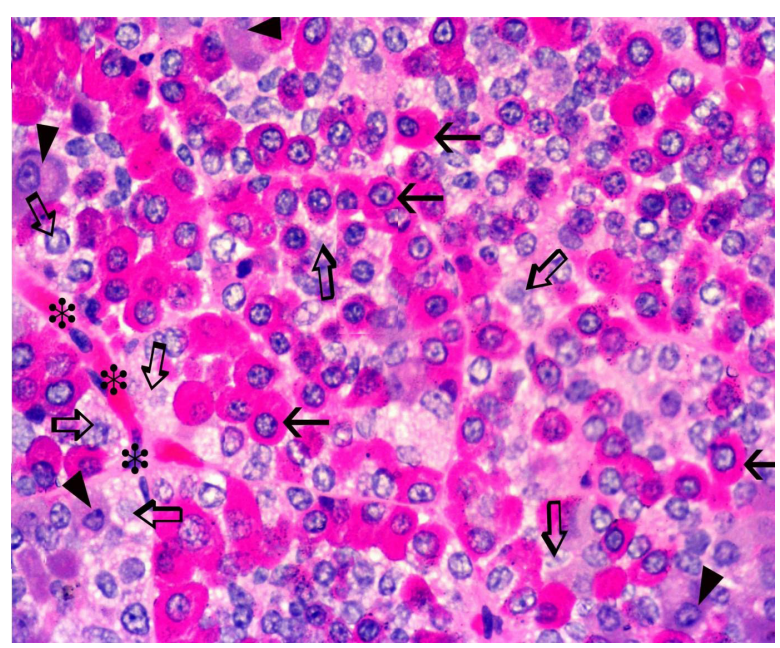

Fig. 1. H\&E stained section demonstrating histological organization and cellular components of the hypophysis. Various types of cells are seen in the adenohypophysis. The chromophils categorized as acidophils (solid arrows) and basophils (arrow head). The acidophils show distinct cell boundaries and stain pink with eosin. The basophils display light blue nuclei and stain purple with hematoxylin. Folliculostellate (FS) cells (Open arrows) appear pale in color and extend long cytoplasmic processes to surround adjacent endocrine cells and being in close contact with blood capillaries (asterisks) $(200 \times)$.

wings of cell clusters of the adenohypophysis, and also scattered in the median part. The other endocrine cells appear to be lactotropes which are usually randomly distributed throughout the adenohypophysis, mostly in the posteromedial and posterolateral aspects (Figs. 2 and 3).

\section{Discussion}

The objective of the present study was to examine, by immunohistochemistry, the cellular localization and distribution pattern of CTLA- $2 \alpha$ in adenohypophysis and deduce its functional implications in the gland. The results showed that the CTLA- $2 \alpha$ is specifically localized at high levels in FS cells in both male and female mice. Folliculostellate cells were recognized by their special tendency to surround adjacent endocrine cells with long cytoplasmic processes. In this study, the endocrine cells surrounded by CTLA- $2 \alpha$-reactive FS cells appeared to be the somatotropes and corticotropes. These cells are usually found in the lateral wings of cell clusters in the adenohypophysis (Melmed, 1995) and some are scattered in the median part. Others thought to be lactotropes which are usually found randomly distributed throughout the adenohypophysis, predominantly in clusters at the posteromedial and posterolateral aspects (Kovacs and Horvath, 1986). CTLA- $2 \alpha$ was not detected in all FS cells, and this could be associated with the endocrine activity of the animal and the function of individual cells at the time

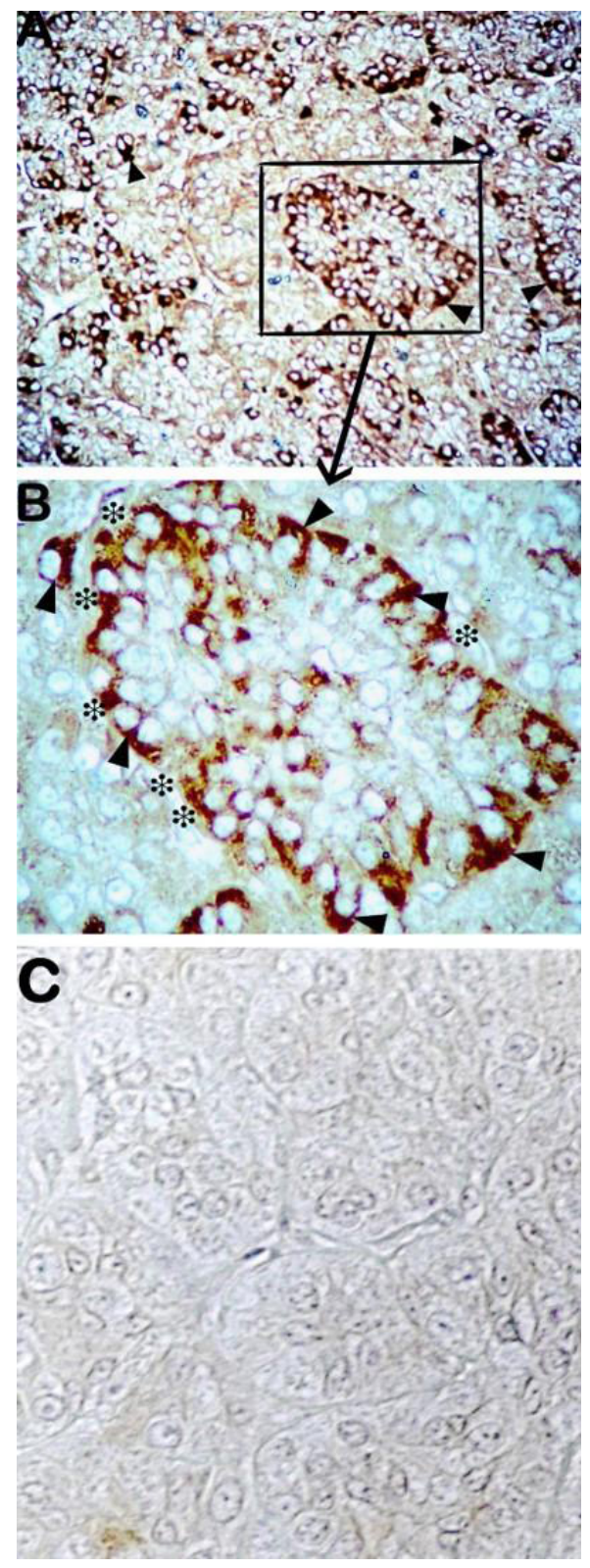

Fig. 2. Immunohistochemical analysis of CTLA-2 $\alpha$ in the adenohypophysis using peroxidase chromogen DAB. (A) CTLA-2 $\alpha$ positive immunoreactivity in FS cells (arrowhead). The FS cells are recognized by their special tendency to surround adjacent endocrine cells with long cytoplasmic processes and being in close contact with blood capillaries (asterisks). The endocrine cells are probably the somatotrophs and corticotrophs, which are usually found in the lateral wings of cell clusters in the adenohypophysis and some scattered in the median part. Others are thought to be lactotrophs seen randomly distributed throughout the adenohypophysis, mostly in the posteromedial and posterolateral aspects. (B) The large magnification of (A). Localization of CTLA- $2 \alpha$ in the cells is not observed in the control section (C) incubated with PBS in place of CTLA-2 $\alpha$ antibody (A: $100 \times$; B and C: $400 \times)$. 


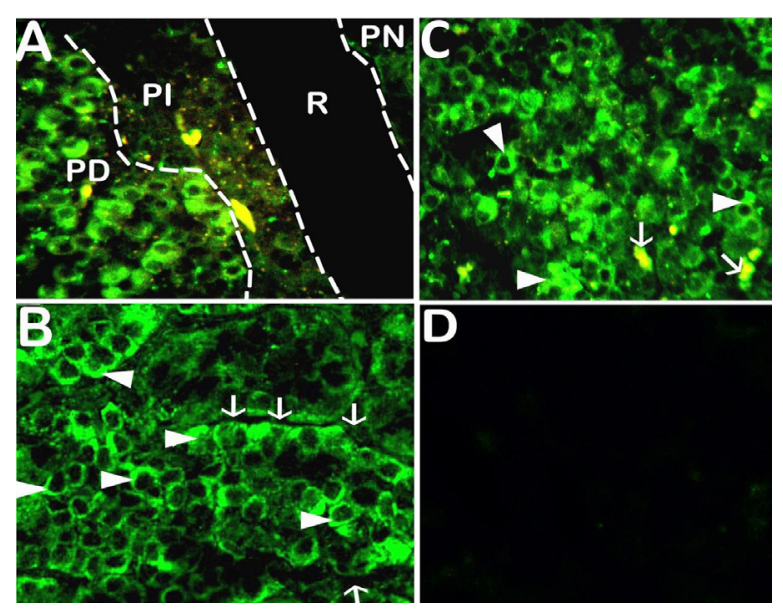

Fig. 3. Immunofluorescence localization of CTLA-2 $\alpha$ in the adenohypophysis. (A) Distinct lobes of the hypophysis including the adenohypophysis which is composed of the pars distalis (PD), the pars intermedia (PI) and pars tuberalis (not shown) and the neural lobe [pars nervosa $(\mathrm{PN})]$ or posterior lobe. Note also the presence of the hypophyseal cleft, the remnant of Rathke's pouch (R). High level of immunoreactivity for CTLA-2 $\alpha$ is seen in the PD and moderate in PI and absent in PN. Plates (B) and (C) Clear localization of CTLA-2 $\alpha$ in the cytoplasm of FS cells (arrow heads) that are recognized by their tendency to extend long cytoplasmic processes to surround adjacent endocrine cells and being in close contact with blood capillaries (white arrows) but is not observed in the control section. (D) Incubated with PBS in place of CTLA- $2 \alpha$ antibody $(200 \times)$.

point when they were sampled. A normal cell responds to stimuli through coordinated changes in gene expression. The regulation of translation is often used under these circumstances because it allows immediate and selective changes in protein levels.

Several functions have been ascribed to FS cells, including phagocytosis (Stokreef et al., 1986; Luziga et al., 2006), stem cell function (Yoshimura et al., 1977), and paracrine regulation of hormone secreting endocrine cells (Baird et al., 1985). FS cells also produce many substances that influence the activity of endocrine cells, including vascular endothelial growth factor (Ferrara and Henzel, 1989), fibroblast growth factor (Ferrara et al., 1987), interleukin-6 (Vankelecom et al., 1993), follistatin (Kaiser et al., 1992), leukemia inhibitory factor (Ferrara et al., 1992), nitric oxide synthase (Ceccatelli et al., 1993; Lloyd et al., 1995), and leptin (Jin et al., 1999). The present immunohistochemical findings on the expression of CTLA- $2 \alpha$ in FS cells expand the previous information regarding the function FS cells in adenohypophysis, indicating that FS cells are multifunctional cells and that their major function remains to be established. Indeed, previous studies show the multifunctional nature of some cells in adenohypophysis by exhibiting mixed phenotypes in which the cells may be involved in paradoxical secretion: a secretion of a hormone evoked by a non-corresponding releasing hormone and transdifferentiation: a phenotypic switch between different mature cell types without cell division (Nunez et al., 2003; Villalobos et al., 2004).

It is also known that cathepsins are involved in proteolytic processing of prohormone precursors into mature hormones (Loh and Gainer, 1982; Sei et al., 2003). Specifically, cathepsin L is shown to participate in various hormone processing pathways, including the biosynthesis of ACTH, $\beta$-endorphin, and $\alpha$-MSH in secretory vesicles (Funkelstein et al., 2008a). The enzymatic activity of cathepsins is regulated by changes in $\mathrm{pH}$ and their interaction with inhibitors (Kos and Lah, 1998; Levicar et al., 2002) and the CTLA-2 $\alpha$ is shown to inhibit the activity of cathepsin L with high affinity (Kurata et al., 2003). Although the functional implications underlying the localization of CTLA$2 \alpha$ in the adenohypophysis is not well established, in light of these, it is reasonable to conclude that through regulation of cathepsin L activity, CTLA- $2 \alpha$ participates in the proteolytic processing of prohormone precursors to active hormones. It is considered that FS cell synthesize CTLA-2 $\alpha$ which exert its effects on endocrine cells to which they surround with long cytoplasmic processes. In a different study, cathepsin $\mathrm{L}$ has been implicated in proneuropeptide processing in secretory vesicles of brain cortical neurons and in adrenal medullary chromaffin cells (Funkelstein et al., 2008a). Interestingly, colocalization of cathepsin L and CTLA- $2 \alpha$ in various regions of the mouse brain has also been demonstrated by the immunofluorescence (Luziga et al., 2016) indicating that the fine equilibrium between the synthesis and secretion of cathespin L and CTLA- $2 \alpha$ is a part of the brain processes to maintain normal growth and development. Taking altogether, these results provide some clues for the possible role of CTLA- $2 \alpha$ with regard to the physiological control of hormone secretion in the adenohypophysis.

In conclusion, this study demonstrates that CTLA- $2 \alpha$ is mainly localized in FS cells in the mouse adenohypophysis. This observation is suggestive of a specialized function of CTLA- $2 \alpha$ in relation to proteolytic processing of prohormone precursors through the regulation of cathepsin activity and also opens ways to new studies on the function of CTLA- $2 \alpha$ in the endocrine system.

\section{Acknowledgments}

The author is grateful to the Japanese Ministry of Education, Culture, Sports, Science and Technology for financial support. The author also would like to thank the Emeritus Professor Yoshimi Yamamoto for his contribution in the antibody production.

Conflict of interest

The author declares that there is no conflict of interest. 


\section{References}

Baird, A., Mormede, P., Ying, S.Y., Wehrenberg, W.B., Ueno, N., Ling, N. and Guillemin, R. 1985. A nonmitogenic pituitary function of fibroblast growth factor: regulation of thyrotropin and prolactin secretion. Proc. Natl. Acad. Sci. USA. 82, 5545-5549.

Ceccatelli, S., Hulting, A.L., Zhang, X., Gustafsson, L., Villar, M. and Hokfelt, T. 1993. Nitric oxide synthase in the rat anterior pituitary gland and the role of nitric oxide in regulation of luteinizing hormone secretion. Proc. Natl. Acad. Sci. USA. 90, 11292-11296.

Chen, B. and Platt, M.O. 2011. Multiplex zymography captures stage-specific activity profiles of cathepsins $\mathrm{K}$, L, and $\mathrm{S}$ in human breast, lung, and cervical cancer. J. Transl. Med. 9, 109.

Cuello, A.C. 1993. Immunohistochemistry II. New York, NY: John Wiley \& Sons, Ltd.

El Etreby, M.F. and El Bab, M.R.F. 1977. Localization of gonadotrophic hormones in the dog pituitary gland: a study using immunoenzyme histochemistry and chemical staining. Cell Tissue Res. 183, 167-175.

Ferrara, N. and Henzel, W.J. 1989. Pituitary follicular cells secrete a novel heparin-binding growth factor specific for vascular endothelial cells. Biochem. Biophys. Res. Commun. 161, 851-858.

Ferrara, N., Schweigerer, L., Neufeld, G., Mitchell, R. and Gospodarowicz, D. 1987. Pituitary follicular cells produce basic fibroblast growth factor. Proc. Natl. Acad. Sci. USA. 84, 5773-5777.

Ferrara, N., Winer, J. and Henzel, W.J. 1992. Pituitary follicular cells secrete an inhibitor of aortic endothelial cell growth: identification as leukemia inhibitory factor. Proc. Natl. Acad. Sci. USA. 89, 698-702.

Funkelstein, L., Toneff, T., Hwang, S.R., Reinheckel, T., Peters, C. and Hook, V. 2008a. Cathepsin L participates in the production of neuropeptide $\mathrm{Y}$ in secretory vesicles, demonstrated by protease gene knockout and expression. J. Neurochem. 106, 384391.

Funkelstein, L., Toneff, T., Mosier, C., Hwang, S.R., Beuschlein, F., Lichtenauer, U.D., Reinheckel, T., Peters, C. and Hook, V. 2008b. Major role of cathepsin $\mathrm{L}$ for producing the peptide hormones ACTH, $\beta$-endorphin, and $\alpha-\mathrm{MSH}$, illustrated by protease gene knockout and expression. J. Biol. Chem. 283, 35652-35659.

Hook, V.Y., Azaryan, A.V., Hwang, S.R. and Tezapsidis, N. 1994. Proteases and the emerging role of protease inhibitors in prohormone processing. FASEB J. 8, 1269-1278

Hook, V., Yasothornsrikul, S., Greenbaum, D., Medzihradszky, K.F., Troutner, K., Toneff, T. and Bogyo, M. 2004. Cathepsin L and Arg/ Lys aminopeptidase: a distinct prohormone processing pathway for the biosynthesis of peptide neurotransmitters and hormones. J. Biol. Chem. 385, 473-480.

Hwang, S.R., Garza, C., Mosier, C., Toneff, T., Wunderlich, E., Goldsmith, P. and Hook, V. 2007. Cathepsin L expression is directed to secretory vesicles for enkephalin neuropeptide biosynthesis and secretion. J. Biol. Chem. 282, 9556-9563.

Japon, M.A., Rubinstein, M. and Low, M.J. 1994. In situ hybridization analysis of anterior pituitary hormone gene expression during fetal mouse development. J. Histochem. Cytochem. 42, 1117-1125.

Jin, L., Burguera, B.G., Couce, M.E., Scheithauer, B.W., Lamsan, J., Eberhardt, N.L., Kulig, E. and Lloyd, R.V. 1999. Leptin and leptin receptor expression in normal and neoplastic human pituitary: evidence of a regulatory role for leptin on pituitary cell proliferation. J. Clin. Endocrinol. Metab. 84, 2903-2911.

Kaiser, U.B., Lee, B.L., Carroll, R.S., Unabia, G., Chin, W.W. and Childs, G.V. 1992. Follistatin gene expression in the pituitary: localization in gonadotropes and folliculostellate cells in diestrous rats. Endocrinology 130, 3048-3056.

Kos, J. and Lah, T.T. 1998. Cysteine proteinases and their endogenous inhibitors: target proteins for prognosis, diagnosis and therapy in cancer. Oncol. Rep. 5, 1349-1361.

Kovacs, K. and Horvath, E. 1986. Tumors of the pituitary gland, fascicle 21, second series: Atlas of tumor pathology. Washington, DC: Armed Forces Institute of Pathology.

Kurata, M., Hirata, M., Watabe, S., Miyake, M., Takahashi, S.Y. and Yamamoto, Y. 2003. Expression, purification, and inhibitory activities of mouse cytotoxic T-lymphocyte antigen-2. Protein Expr. Purif. 32, 119-125.

Levicar, N., Strojnik, T., Kos, J., Dewey, R.A., Pilkington, G.J. and Lah, T.T. 2002. Lysosomal enzmyes, cathepsins in brain tumour invasion. J. Neurooncol. 58, 21-32.

Levy, A. 2002. Physiological implications of pituitary trophic activity. J. Endocrinol. 174, 147-155.

Lloyd, R.V., Jin, L., Qian, X., Zhang, S. and Scheithauer, B.W. 1995. Nitric oxide synthase in the human pituitary gland. Am. J. Pathol. 146, 86-94.

Loh, Y.P. and Gainer, H. 1982. Characterization of pro-opiocortin-converting activity in purified secretory granules from rat pituitary neurointermediate lobe. Proc. Natl. Acad. Sci. USA. 79, 108-112.

Luziga, C., Nakamura, O., Deshapriya, R.M.C., Usui, M., Miyaji, M., Wakimoto, M., Wada, N., Mbassa, G. and Yamamoto, Y. 2008. Dendritic andaxonal localization of cytotoxic T-lymphocyte antigen-2 alpha protein in mouse brain. Brain Res. 1204, 40-52. 
Luziga, C., Nga, B.T., Mbassa, G. and Yamamoto, Y. 2016. Cathepsin L coexists with Cytotoxic T-lymphocyte Antigen-2 alpha in distinct regions of the mouse brain. Acta Histochemica. 118, 704-710.

Luziga, C., Yamamoto, Y., Horii, Y., Mbassa, G. and Mamba, K. 2006. Phagocytotic removal of apoptotic endocrine cells by folliculostellate cells and its functional implications in clusterin accumulation in pituitary colloids in helmeted guinea fowl (Numida meleagris). Acta Histochemica. 108, 69-80.

Melmed, S. 1995. The pituitary. 3rd Edn., Massachuset: Black Well Science.

Nunez, L., Villalobos, C., Senovilla, L. and Garcia-Sancho, J. 2003. Multifunctional cells of mouse anterior pituitary reveal a striking sexual dimorphism. J. Physiol. 549, 835-843.

Sander, B., Andersson, J. and Andersson, U. 1991. Assessment of cytokines by immunofluorescence and the paraformaldehyde-saponin procedure. Immunol. Rev. 119, 65-93.

Sei, C., Toneff, T., Aaron, W. and Hook, V.Y. 2003. Regulation of ACTH levels in anterior pituitary cells during stimulated secretion: evidence for aspartyl and cysteine proteases in the cellular metabolism of ACTH. Peptides 24, 717-725.

Stokreef, J.C., Reifel, C.W. and Shin, S.H. 1986. A possible phagocytic role for folliculo-stellate cells of anterior pituitary following estrogen withdrawal from primed male rats. Cell Tissue Res. 243, $255-261$.

Slaoui, M. and Fiette, L. 2011. Histopathology procedures: from tissue sampling to histopathological evaluation. Methods Mol. Biol. 691, 69-82.

Takahashi, S.Y., Yamamoto, Y., Shionoya, Y. and Kageyama, T. 1993. Cysteine proteinase from the eggs of the silkmoth, Bombyx mori: identification of a latent enzyme and characterization of activation and proteolytic processing in vivo and in vitro. $\mathrm{J}$. Biochem. 144, 267-272.

Vankelecom, H., Matthys, P., Van Damme, J.V., Heremans, H., Billiau, A. and Denef, C. 1993. Immunocytochemical evidence that S-100-positive cells of the mouse anterior pituitary contain interleukin-6 immunoreactivity. J. Histochem. Cytochem. 41, 151-156.

Villalobos, C., Nunez, L. and Garcia-Sancho, J. 2004. Anterior pituitary thyrotropes are multifunctional cells. Am. J. Physiol. Endocrinol. Metab. 287, E1166-1170.

Yasothornsrikul, S.L., Greenbaum, D., Medzihradszky, K.F., Toneff, T., Bundey, R., Miller R., Schilling, B., Petermann, I., Dehnert, J., Logvinova, A., Goldsmith, P., Neveu, J.M., Lane, W.S., Gibson, B., Reinheckel, T., Peters, C., Bogyo, M. and Hook, V. 2003. Cathepsin L in secretory vesicles functions as a prohormone-processing enzyme for production of the enkephalin peptide neurotransmitter. Proc. Natl. Acad. Sci. USA. 100, 9590-9595.

Yoshimura, F., Soji, T. and Kiguchi, Y. 1977. Relationship between the follicular cells and marginal layer cells of the anterior pituitary. Endocrinol. Jpn. 24, 301-305. 